\title{
Concussion Education: A (Gentle) Knock on the Head For All of Us
}

Can J Neurol Sci. 2012; 39: 698-699

In our society, when a professional athlete is injured many sports fans take note. However, when a high-profile, elite athlete is injured a larger segment of the population becomes aware and takes interest. Such was the case in 2011 when Canadian ice hockey player Sidney Crosby, captain of the Pittsburgh Penguins, was injured twice, in two games only a few days apart. He was diagnosed with a concussion and, following the National Hockey League protocol, had to sit out until he was free of symptoms. Not only did this focus attention on the topic of concussion in the sporting world, but it drew attention to the topic in main-street Canada and abroad. But just what does the general populace know about concussion? Perhaps people were asking themselves: what is a concussion?; what are the symptoms that force an athlete to be sidelined?; what is the procedure to overcome a concussion and get back into the game?

Many people in Canada and abroad have children playing contact sports, serve as coaches or trainers or are engaged in those sports themselves. They see more and more reports of athletes getting concussed; reports of former athletes suffering from neurological disorders years after multiple blows to the head; or reports of athletes dying early or committing suicide for reasons where accumulated acquired brain injury may be a contributing factor. Where do people turn to for information about these topics? The easiest source, of course, is the media. But the media is replete with fact, fiction and traditional views on what it takes to be a (real) athlete engaged in contact sports such as ice hockey and football. A person may see on television an interview with a neurosurgeon/neurologist or other physician who is an expert in the field cautioning about concussion and head-injury, or they may (more likely) see, during the intermission of a contact sporting event, analysis that downplays the seriousness of body contact and head blows in the sport. Who are they to believe? Surely their own physician can provide them with accurate information.

Not so fast. An article published in this edition of the Canadian Journal of Neurological Sciences provides cause to pause $^{1}$. This work, out of the University of Toronto and done under the supervision of Dr. Charles Tator, surveyed all 17 Canadian medical schools and asked a simple question: do you teach medical students about concussion? Given the timeliness of this topic the results they found were somewhat of a surprise. Three schools did not respond (even though the data were kept anonymous). Of the 14 responding schools, four provided no concussion teaching in their curriculum, four provided concussion-specific education and six offered head injury education that incorporated a concussion component, though the exact nature of that component could not be determined. Therefore, it would seem that only 4 out of 17 (24\%) Canadian medical schools can be deemed with a degree of certainty to be addressing the topic of concussion head-on. The authors hypothesize reasons for their finding. One suggestion is that the topic of concussion overlaps different specialities and each speciality may believe the other is teaching the topic. A second suggestion is that medical schools align their curriculum to the Medical Council of Canada (MCC) objectives for the MCC Qualifying Examination (MCCQE) and concussion is not sufficiently emphasized in the MCC database. Whatever the reason, it is not for the lack of publications on the topic of concussion and head-injury. We and others have published review articles and consensus statements on the topic of headinjury and concussion ${ }^{2-5}$. What may be more at issue is the transfer of this knowledge to students, medical trainees and the population-at-large.

Earlier this year Boggild and Tator surveyed graduating medical students and neurology and neurosurgery residents at the University of Toronto to assess their knowledge and awareness of the diagnosis and treatment of concussion ${ }^{6}$. They concluded that a significant number of medical students and residents had an incomplete knowledge about both. In 2009, Cusimano and coworkers also used a questionnaire to assess concussion knowledge among a segment of the population that participated in minor league ice hockey ${ }^{7}$. They surveyed 267 players and 142 adults (coaches, trainers and parents) and also found that a significant number of people held misconceptions about concussion in hockey which could lead to serious health consequences. In another paper published in 2009, the authors performed a qualitative literature review of 52 journal articles, 20 websites and 2 books in order to assess the quality of knowledge transfer as it pertains to concussion education ${ }^{8}$. They found that knowledge transfer is a relatively new concept in sports medicine and its influence on enhancing concussion education is not well known. In other words we need to be doing a better job teaching ourselves as physicians so that we can better teach our patients and, perhaps just as importantly, the population-at-large about concussion and head-injury.

The purpose of this editorial is not to teach the reader about the current concepts around the diagnosis and management of concussion and head-injury. However, given the finding that many medical professionals reading it may not have had concussion education at medical school, it might be doing a better service if it were! Fortunately Dr. Tator and colleagues have already started to help the medical community move forward in regards to head-injury and concussion education. Dr. Tator is the founder of ThinkFirst Canada an organization whose vision and goal is for a future free of traumatic brain and spinal cord injuries among our children and youth through the creation, dissemination, and evaluation of educational initiatives, public advocacy, and by giving kids and those who care for them the tools and information they need to use their minds to protect their bodies (http://www.thinkfirst.ca). Medical students, residents, fellows and practicing physicians can access educational resources on the website that will teach them about concussion - 
information that they can then pass on to patients. The website is also a resource for athletes, coaches and parents. In their paper Burke and coworkers also refer to a one-hour concussionspecific lecture that has been endorsed by the Concussion Education and Awareness Committee of ThinkFirst Canada and the Ontario Neurotrauma Foundation ${ }^{1}$. This lecture will be available for free download on the website and is being circulated to all Canadian medical schools. Another suggestion to improve concussion education and awareness is to expose medical students to individuals who have suffered concussion ${ }^{1}$. We have done this at our institution. Through the initiative of one of my colleagues involved in undergraduate medical education, Dr. Wai $\mathrm{Ng}$, we were able to arrange a talk and question-period with former professional ice hockey player Eric Lindros (who had been concussed as a player), whose (very well attended) presentation highlighted some of the acute and long-term effects of concussion.

Knowledge of concussion and head-injury also positions the medical student and physician to be a better health care advocate, one of the CanMEDs physician roles. Recent papers draw attention to the impact of concussions on players in the National Hockey League ${ }^{9}$, but perhaps more importantly to players in youth ice hockey programs ${ }^{10}$. Though only 1 in 4000 youth ice hockey players makes it to the professional league, the road to the NHL may be rough for many ${ }^{10}$. By one estimate concussion affects up to $25 \%$ of players in youth ice hockey programs, with some Canadian provinces allowing players as young as nine years to engage in bodychecking ${ }^{10}$. Bodychecking in minor hockey introduces substantial risks of serious injury, including the risk of concussion and lasting brain damage ${ }^{10}$. Perhaps it is time for more physicians to advocate on behalf of those young players who engage in ice hockey in an effort to restrict bodychecking only to those players at an elite level.

Obviously sport is not the only place where concussions and head-injury can occur. There is a growing body of literature on "non-sport" concussions ${ }^{11}$ and the physician's knowledge on head-injury will be useful in general practice. But it is clearly in contact sports where discussion around head-injury and concussion are magnified. Society is unlikely to do away with contact sports and injuries can occur in non-contact sports anyway. Aggression is thought to be an evolutionary part of human life ${ }^{12}$ and contact sports can be a manifestation of some of aspects of life, at least to a certain degree. But sport can also be a great builder of health and character, as well as being fun. We should embrace sport as long we can optimize its safety. A better understanding of head-injury and concussion by physicians, sports administrators, coaches, trainers and players will go a long way to that end.

\section{REFERENCES}

1. Burke MJ, Chundamala J, Tator $\mathrm{CH}$. Deficiencies in concussion education in Canadian medical schools. Can J Neuol Sci. 2012; 39(6):763-6.

2. Meyer M, Megyesi J, Meythaler J, et al. Acute management of acquired brain injury. Part I: an evidence-based review of nonpharmacological interventions. Brain Inj. 2010;24:694-705.

3. Meyer M, Megyesi J, Meythaler J, et al. Acute management of acquired brain injury. Part II: an evidence-based review of pharmacological interventions. Brain Inj. 2010;24:706-21.

4. Meyer M, Megyesi J, Meythaler J, et al. Acute management of acquired brain injury. Part III: an evidence-based review of interventions used to promote arousal from coma. Brain Inj. 2010;24:722-9.

5. McCrory P, Meeuwisse W, Johnston K, et al. Consensus statement on concussion in sport: 3rd International Conference on Concussion in Sport held in Zurich, November 2008. Clin J Sport Med. 2009; 19:185-200.

6. Boggild $\mathrm{M}$, Tator $\mathrm{CH}$. Concussion knowledge among medical students and neurology/neurosurgery residents. Can J Neurol Sci. 2012:39:361-8.

7. Cusimano MD, Chipman ML, Volpe R, Donnelly P. Canadian minor hockey participants' knowledge about concussion. Can J Neurol Sci. 2009;36:315-20.

8. Provvidenza CF, Johnston KM. Knowledge transfer principles as applied to sport concussion education. Br J Sports Med. 2009; 43 Suppl 1:i68-75.

9. Benson BW, Meeuwisse WH, Rizos J, Kang J, Burke CJ. A prospective study of concussions among National Hockey League players during regular season games: the NHL-NHLPA Concussion Program. CMAJ. 2011;183:905-11.

10. Johnson LSM. Concussion in youth ice hockey: it's time to break the cycle. CMAJ. 2011;183:921-4.

11. Sojka P. "Sport" and "non-sport" concussions. CMAJ. 2011;183: $887-8$.

12. Buss DM, Shackelford TK. Human aggression in evolutionary psychological perspective. Clin Psych Rev. 1997;17:605-19. 